\title{
Stable carbon isotope fractionation in the UV photolysis of CFC-11 and CFC-12
}

\author{
A. Zuiderweg ${ }^{1}$, J. Kaiser ${ }^{2}$, J. C. Laube ${ }^{2}$, T. Röckmann ${ }^{1}$, and R. Holzinger ${ }^{1}$ \\ ${ }^{1}$ Institute of Marine and Atmospheric research Utrecht (IMAU), Utrecht University, Utrecht, The Netherlands \\ ${ }^{2}$ School of Environmental Sciences, University of East Anglia, Norwich, UK
}

Correspondence to: A. Zuiderweg (azuider@gmail.com)

Received: 24 November 2011 - Published in Atmos. Chem. Phys. Discuss.: 16 December 2011

Revised: 3 May 2012 - Accepted: 4 May 2012 - Published: 16 May 2012

\begin{abstract}
The chlorofluorocarbons CFC-11 $\left(\mathrm{CFCl}_{3}\right)$ and CFC-12 $\left(\mathrm{CF}_{2} \mathrm{Cl}_{2}\right)$ are stable atmospheric compounds that are produced at the earth's surface, but removed only at high altitudes in the stratosphere by photolytic reactions. Their removal liberates atomic chlorine that then catalytically destroys stratospheric ozone. For such longlived compounds, isotope effects in the stratospheric removal reactions have a large effect on their global isotope budgets. We have demonstrated a photolytic isotope fractionation for stable carbon isotopes of $\mathrm{CFC}-11$ and CFC-12 in laboratory experiments using broadband UVC (190-230 nm) light. ${ }^{13} \mathrm{C} /{ }^{12} \mathrm{C}$ isotope fractionations $(\varepsilon)$ range from $(-23.8 \pm 0.9)$ to $(-17.7 \pm 0.4) \%$ for $\mathrm{CFC}-11$ and $(-66.2 \pm 3.1)$ to $(-51.0 \pm 2.9) \%$ for CFC-12 between 203 and $288 \mathrm{~K}$, a temperature range relevant to conditions in the troposphere and stratosphere. These results suggest that CFCs should become strongly enriched in ${ }^{13} \mathrm{C}$ with decreasing mixing ratio in the stratosphere, similar to what has been recently observed for $\mathrm{CFC}$ chlorine isotopes. In conjunction with the strong variations in CFC emissions before and after the Montréal Protocol, the stratospheric enrichments should also lead to a significant temporal increase in the ${ }^{13} \mathrm{C}$ content of the CFCs at the surface over the past decades, which should be recorded in atmospheric air archives such as firn air.
\end{abstract}

\section{Introduction}

The chlorofluorocarbons CFC-11 $\left(\mathrm{CFCl}_{3}\right)$ and CFC-12 $\left(\mathrm{CF}_{2} \mathrm{Cl}_{2}\right)$ are the most abundant anthropogenic halocarbons in the atmosphere. Before their production was banned under the Montréal Protocol and its amendments, the usage of these compounds as refrigerants, cleansers, aerosol propellants and foam-blowing agents worldwide resulted in significant atmospheric loading; at their peaks in 1990 and 2003, respectively, mean mixing ratios in the troposphere were approximately $260 \mathrm{ppt}\left(\mathrm{ppt}=\right.$ pmole mole ${ }^{-1}=10^{-12}$ mole mole $\left.{ }^{-1}\right)$ for CFC11 and 550 ppt for CFC-12 (Forster et al., 2007; AGAGE, 2010). Due to the buildup of these and other anthropogenic halocarbons, total organic chlorine levels in the troposphere increased from approximately $600 \mathrm{ppt}$ in 1900 to nearly 3350 ppt in 2008. CFC-11 and CFC-12 account for approximately $55 \%$ of the total, outweighing contributions by natural compounds such as methyl chloride, $\mathrm{HCl}$ and naturally emitted molecular chlorine (Butler et al., 1999; WMO 2010).

Chlorofluorocarbons such as CFC-11 and CFC-12 are produced by anthropogenic processes at the earth's surface, but have their only significant sinks in the stratosphere, at altitudes where UV-C radiation $(\lambda<220 \mathrm{~m})$ is sufficiently abundant to dissociate the $\mathrm{C}-\mathrm{Cl}$ bond: Reaction (R1). A minor sink (approximately 3-7\%) is due to $\mathrm{Cl}$ abstraction by $\mathrm{O}\left({ }^{1} D\right)$, which is produced from the photolysis of ozone in the stratosphere: Reaction (R2) (Seinfeld and Pandis, 1998; Laube et al., 2010a).

$$
\begin{aligned}
& \mathrm{CF}_{m} \mathrm{Cl}_{4-m}+h v \stackrel{\lambda<220 \mathrm{~nm}}{\longrightarrow} \mathrm{CF}_{m} \mathrm{Cl}_{3-m}+\mathrm{Cl} \\
& \mathrm{CF}_{m} \mathrm{Cl}_{4-m}+\mathrm{O}\left({ }^{1} D\right) \longrightarrow \mathrm{CF}_{m} \mathrm{Cl}_{3-m}+\mathrm{ClO}
\end{aligned}
$$

These reactions cause the initial release of chlorine to begin the now well-known catalytic decomposition of ozone first proposed by Molina and Rowland (1974).

In addition, CFC-11 and CFC-12 have a significant global warming potential (4750 and 10900 times that of $\mathrm{CO}_{2}$ per 
$\mathrm{kg}$, respectively, over a 100 year time horizon), resulting together in an atmospheric radiative forcing of approximately $0.233 \mathrm{~W} \mathrm{~m}^{-2}$ in 2005 and thus contributing to anthropogenic climate change (Massie and Goldman, 1992; Forster et al., 2007).

Since the implementation of the Montréal Protocol in 1987, the mixing ratios of CFC-11 and CFC-12 in the troposphere have decreased from their peak values to $240 \mathrm{ppt}$ and $530 \mathrm{ppt}$, respectively, as sources have decreased in strength and the stratospheric sink has become dominant (Engel et al., 1998; Forster et al., 2007; AGAGE 2010). However, due to the long atmospheric lifetimes of these compounds (45 and 100 years for CFC-11 and CFC-12, respectively, WMO 2010), it is expected that atmospheric effects caused by the presence of these CFCs will persist for decades to centuries (Engel et al., 1998; Forster et al., 2007).

The stable isotope composition of species in the atmosphere can be altered by chemical reactions due to differences in chemical bond strengths ascribed to isotopic substitution, causing fractionation between the different isotopologues of a given molecule (Brenninkmeijer et al., 2003). Isotope values are conveniently expressed in $\delta$ notation, in the case of ${ }^{13} \mathrm{C}$ :

$\delta^{13} \mathrm{C}=\frac{{ }^{13} R_{\text {sample }}}{{ }^{13} R_{\text {standard }}}-1$

where ${ }^{13} R$ is the ${ }^{13} \mathrm{C} /{ }^{12} \mathrm{C}$ ratio in a sample or standard material, respectively. The internationally accepted reference material for ${ }^{13} \mathrm{C}$ is Vienna Pee Dee Belemnite (VPDB), and the $\delta$ value is commonly multiplied by $1000 \%$ o to express it in per mille (\%o) for readability. Assuming a Rayleigh-type fractionation, the isotope fractionation $\varepsilon$ relates the change in $\delta$ value and mixing ratio during a photolysis reaction as follows:

$\ln \left(\frac{\delta^{13} \mathrm{C}+1}{\delta^{13} \mathrm{C}_{0}+1}\right)=\varepsilon \ln (F)$

where $\delta^{13} \mathrm{C}_{0}$ and $\delta^{13} \mathrm{C}$ are the stable carbon isotope ratios of the compound before and after photolysis, respectively, and $F$ is the fraction remaining after photolysis. $\varepsilon$ is also commonly expressed in \%o.

CFC-11 and CFC-12 have similar atmospheric cycles as $\mathrm{N}_{2} \mathrm{O}$, which is also long-lived (120 years lifetime) and has mainly surface sources and stratospheric sinks. In the case of $\mathrm{N}_{2} \mathrm{O}$, laboratory experiments, field measurements and modelling studies have shown strong heavy isotope enrichments in the stratosphere, which have an important effect on the isotopic composition in the troposphere (e.g. Rahn and Wahlen, 1997; Röckmann et al., 2001; Kaiser et al., 2003 and 2006; Blake et al., 2003; von Hessberg et al., 2004; Morgan et al., 2004). For CFC-12, recent measurements of the stable chlorine isotope ratio $\left({ }^{37} \mathrm{Cl} /{ }^{35} \mathrm{Cl}\right)$ of stratospheric CFC-12 have shown strong ${ }^{37} \mathrm{Cl}$ enrichments. Associated with the well-established decrease in mixing ratio above the tropopause, a progressive increase in the ${ }^{37} \mathrm{Cl} /{ }^{35} \mathrm{Cl}$ ratio by up to $27 \%$ relative to tropospheric air was observed over $14-34 \mathrm{~km}$ altitude, with an apparent isotope fractionation of $\varepsilon_{\text {app }}=(-12.1 \pm 1.7) \%$ (Laube et al., 2010a).

In this study we report a carbon $\left({ }^{13} \mathrm{C} /{ }^{12} \mathrm{C}\right)$ isotope fractionation $(\varepsilon)$ in CFC-11 and CFC-12 during laboratory broadband UV-C (190-230 nm) photolysis at atmospherically relevant temperatures.

\section{Method}

Photolysis experiments were carried out in March 2011 with a mixture of CFC-11 and CFC-12 in nitrogen, utilizing a photolysis setup at the University of East Anglia in Norwich, UK. The gas mixture used in the experiments was prepared using a custom dilution system with sample loops of 2.5 and $0.1 \mathrm{~mL}$ (Laube et al., 2010b). This system is built into a HP5890 GC oven and is maintained at $353 \mathrm{~K}$ to ensure that compounds are in the gas phase when they are diluted. It uses a Valco 6-port valve for switching sample loops, Nupro valves for controlling input and extraction of compounds, a scroll pump for evacuation, and oxygen-free nitrogen (BOC Gases Inc.) for dilution.

Using this system, $5 \mu \mathrm{mol}$ CFC- 11 and $0.2 \mu \mathrm{mol}$ of CFC12 were mixed in turn with nitrogen into a single $3 \mathrm{~L}$ canister at $300 \mathrm{kPa}$ total pressure, which yielded mixing ratios of $13 \mathrm{ppm}$ for CFC-11 and $530 \mathrm{ppb}$ for CFC-12, both with an error of $\pm 10 \%$. These high mixing ratios were chosen in order to provide adequate material for analysis, while keeping sample volumes small. The use of oxygen-free nitrogen in the mixture excludes the $\mathrm{O}\left({ }^{1} D\right)$ reaction described in Reaction (R2) from taking place in the reaction chamber. The gas amount of the prepared mixture was sufficient for all experiments.

Figure 1 shows a diagram of the photolysis setup. The quartz-glass reactor, which has a volume of $125 \mathrm{~mL}$ (total system volume including lines is approximately $160 \mathrm{~mL}$ ), is temperature controlled through an ethanol regulator and cooler. Pressures in the reactor system are measured through an array of pirani, piezo and CMR pressure sensors; evacuation of the entire system is facilitated through a scroll pump. Photolysis of the CFC mixture is induced by a water-cooled $1 \mathrm{~kW}$ antimony (hereafter Sb) lamp (mfr. Heraeus, Hanau, Germany) with a broadband emission spectrum covering the range 190 to $230 \mathrm{~nm}$, which is ideal for inducing photolysis in CFCs. A spectrum of the Sb lamp emission and solar flux at 20 and $30 \mathrm{~km}$ for the relevant wavelengths and the absorption spectra of CFC-11 and -12 are shown in Fig. 2. The normalized product of the absorption spectra with Sb lamp and $30 \mathrm{~km}$ flux (folded spectra) is shown in Fig. 3. This lamp has previously been used for photolysis experiments with $\mathrm{N}_{2} \mathrm{O}$ (Röckmann et al., 2000 and 2001; Kaiser et al., 2002 and 2003). 
Table 1. Summary of photolysis rates and isotope fractionations from fits in Fig. 5.

\begin{tabular}{lccccccc}
\hline & \multicolumn{3}{c}{ CFC-11 } & & \multicolumn{3}{c}{ CFC-12 } \\
\cline { 2 - 4 } \cline { 7 - 8 } Temp (K) & 203 & 233 & 288 & & 203 & 233 & 288 \\
$J\left(\mathrm{~s}^{-1}\right)$ & $2.8 \times 10^{-4}$ & $3.4 \times 10^{-4}$ & $4.5 \times 10^{-4}$ & & $4.4 \times 10^{-5}$ & $6.6 \times 10^{-5}$ & $9.3 \times 10^{-5}$ \\
$\varepsilon(\%$ ) & $-23.8 \pm 0.9$ & $-23.0 \pm 1.1$ & $-17.7 \pm 0.4$ & & $-66.2 \pm 3.1$ & $-55.3 \pm 3.0$ & $-51.0 \pm 2.9$ \\
$\varepsilon$ fit $r^{2}$ & 0.992 & 0.992 & 0.999 & & 0.993 & 0.984 & 0.993 \\
\hline
\end{tabular}

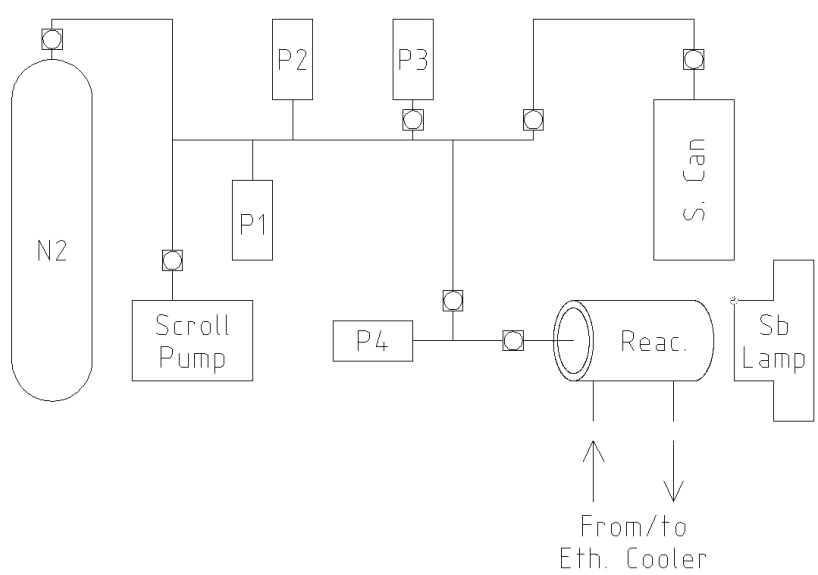

Fig. 1. Diagram of the photolysis setup at the School of Enviromental Sciences at the University of East Anglia. P1-P4 indicate pressure sensors, $S$. Can the sample canister. During filling of the reactor, the source canister containing the unphotolyzed CFC-mixture is installed in place of the sample canister.

The gas mixture, at pressures near $100 \mathrm{kPa}$, was irradiated with UV light with exposure times varying from 0 to $3 \mathrm{~h}$ while the reactor was kept at various temperatures (203, 233, and $288 \mathrm{~K}$ ): at 203 and $233 \mathrm{~K}$ the exposure times were $0-3 \mathrm{~h}$ with $0.5 \mathrm{~h}$ intervals ( 7 samples each), and at $288 \mathrm{~K}$ the exposure times were $0,1.5$, and $3 \mathrm{~h}$. This gave a total of 17 samples.

After each experiment, the content of the reactor was expanded into a $1.75 \mathrm{~L}$ evacuated stainless steel canister. These were subsequently topped up to $200 \mathrm{kPa}$ pressure with oxygen-free nitrogen, to provide adequate volumes and mixing ratios for the analysis system.

The sample canisters were measured in April 2011 in the isotope laboratory of the Institute for Marine and Atmospheric Research Utrecht (IMAU) of Utrecht University (The Netherlands) for mixing ratio and $\delta^{13} \mathrm{C}$ using the system described in Zuiderweg et al. (2011). This instrument was originally designed for the measurement of stable carbon isotope ratios of non-methane hydrocarbons. It features a novel method of removing unwanted compounds (e.g. $\mathrm{CO}_{2}$ and $\mathrm{CH}_{4}$ ) by use of a $3 \mathrm{~m} \times 6.35 \mathrm{~mm}$ packed Porapak Q pre-column, where compounds to be excluded from analysis are separated from the compounds of interest gas chromatographically. Separation of compounds is accomplished

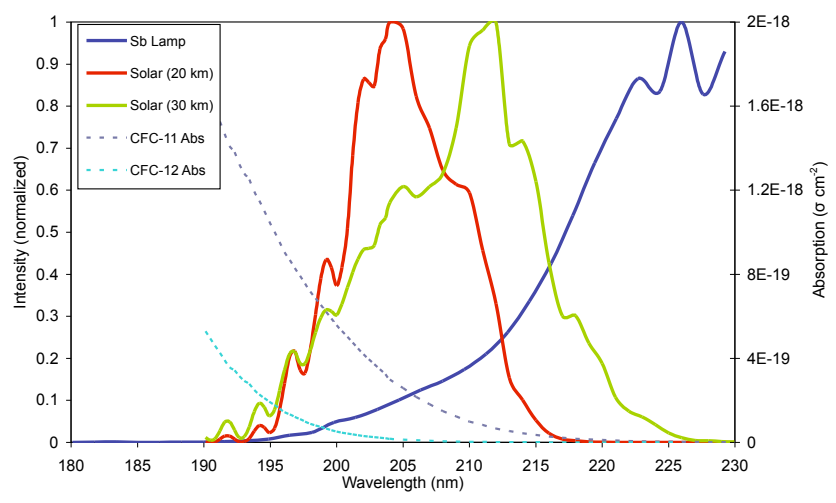

Fig. 2. Normalized UV-C intensity of the Sb lamp and actinic UV-C (Minschwaner et al., 1993) in the altitude range where CFC photolysis takes place (19-34 km), and absorption spectra for CFC-11 and -12 in the relevant wavelength range.

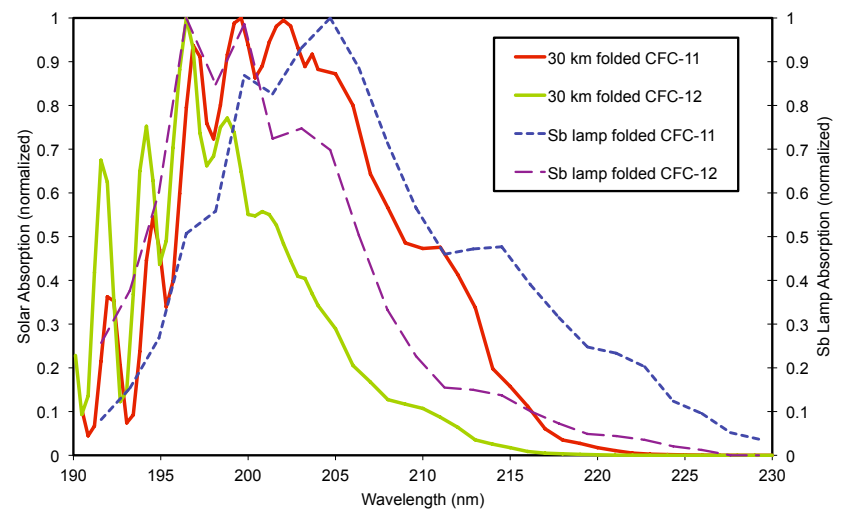

Fig. 3. Product of CFC-11 and -12 absorption spectra and solar and SB lamp spectra, normalized.

by using a $52.5 \mathrm{~m} \times 0.25 \mathrm{~mm}$ Poraplot Q column, the effluent of which is split to (1) a HP 5970 quadrupole MS and (2) a Thermo Finnigan Delta Plus XL isotope ratio mass spectrometer by way of a Pt-Cu-Ni combustor and open split. Peak integration is accomplished through the ISODAT software package. $\delta^{13} \mathrm{C}$ results from this instrument are reported relative to the international Vienna Pee Dee Belemnite standard (VPDB) in per mil (\%o). Details of calibration procedures are elaborated in Zuiderweg et al. (2011).

This system was tested for measurement capability of $C_{1}$ chlorofluorocarbons with a PraxAir Inc. calibration mixture 


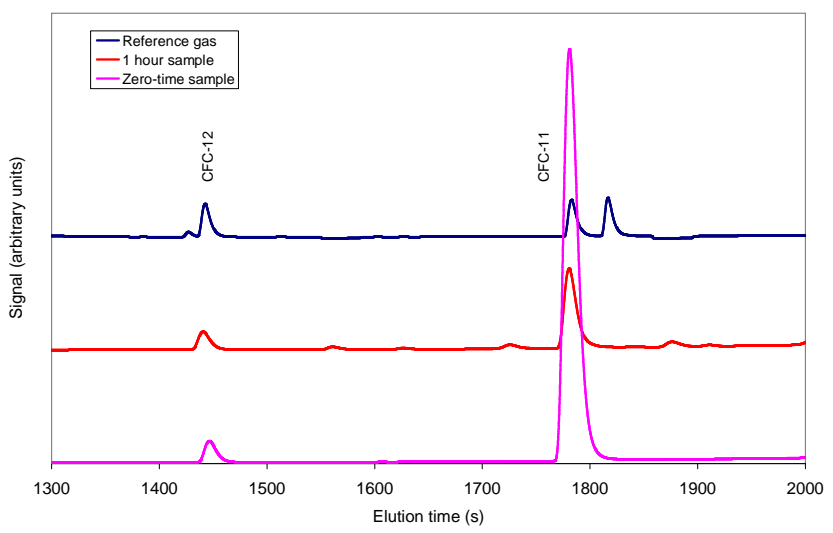

Fig. 4. Example chromatogram from instrument of the Praxair calibration mixture $(0.1 \mathrm{~L}), 1 \mathrm{~h}$ exposure sample at $233 \mathrm{~K}(1 \mathrm{~L})$, and zero-time exposure sample at $233 \mathrm{~K}(1 \mathrm{~L})$ respectively, demonstrating separation performance.

containing $150 \pm 8 \mathrm{ppb}$ of both CFC-11 and CFC-12, among other compounds. Testing results with various volumes showed that the isotopic results were volume independent and stable for $\mathrm{CFC}$ measurement, with $\delta^{13} \mathrm{C}$ repeatability $(1 \sigma, n=30)$ of 0.9 and $0.7 \%$ for CFC- 11 and CFC- 12 , respectively, above peak areas of $0.5 \mathrm{Vs}$ ( $2 \mathrm{ng} \mathrm{C}$ equivalent), and mixing ratio measurement precision of $\pm 5 \%$. Sensitivity of the instrument is approximately $0.25 \mathrm{Vs} /(\mathrm{ng} \mathrm{C}$ ) (Zuiderweg et al., 2011). A sample chromatogram demonstrating compound separation can be found in Fig. 4. Daily calibration of the instrument was accomplished by measuring the above standard before the start and after the finish of that day's measurement series. Blank measurements showed no remnant CFC or interfering peaks.

To ensure that peak areas for the samples exposed longest were still above the specified threshold limit of $0.5 \mathrm{Vs}$, each analysis consumed $1 \mathrm{~L}(100 \mathrm{kPa}, 295 \mathrm{~K})$ of analyte, which allowed for 2 measurements of each of the sample canisters, under normal circumstances.

The theoretical zero photolysis time mixing ratios used for calculating $F$ (the unphotolysed fraction remaining) were established by calculating the number of moles of each CFC in the reactor prior to exposure given a particular reactor temperature. Subsequently, the number of moles of each CFC in the reactor post-exposure was back-calculated from the VMR measurements of each can. All calculations took into account pressure gauge offsets.

\section{Results and discussion}

The photolysis rate coefficient $J$ is given by:

$J=-\frac{\ln (F)}{t}$

and the isotope fractionation $\varepsilon$ is given by Eq. (2). Therefore, we have plotted the natural logarithm of fraction remaining, $\ln (F)$, against photolysis time (Fig. 5a and b) and $\ln \left(\delta^{13} \mathrm{C}\right.$ +1 ) against $\ln (F)$ (Fig. 5c and d) respectively for both compounds at all three temperatures, in order to obtain $J$ and $\varepsilon$ through the slope of linear fits to the data. A summary of least-squares fit parameters for the photolysis rate coefficient and isotope fractionation is given in Table 1. For CFC-11, a neighbouring peak interferes in samples with $\ln (F)<-3$. This interference disturbs the peak integration, leads to incorrect $\delta^{13} \mathrm{C}$ values, and consequently affects $\varepsilon$ obtained from the plotted data. The samples affected and thus rejected have exposure times above $2 \mathrm{~h}$, at 233 and $288 \mathrm{~K}$.

Figure $5 \mathrm{a}$ and $\mathrm{b}$ show the photolysis behavior of CFC-11 and CFC-12 with exposure time. As expected, the Sb-lamp is very effective in photolyzing CFC-11 and -12 , with $95 \%$ and $33 \%$ photolysis of the respective compounds achieved at exposures of $3 \mathrm{~h}$ at the coldest reactor temperature of $203 \mathrm{~K}$. At higher temperatures, photolysis occurs faster and thus compound destruction is more complete for a given exposure time. This is in good agreement with absorption cross sections measured at the respective temperatures (Atkinson et al., 2005 and 2008). Photolysis rates measured range from $2.8 \times 10^{-4}$ to $4.5 \times 10^{-4} \mathrm{~s}^{-1}$ for CFC- 11 and $4.4 \times 10^{-5}$ to $9.3 \times 10^{-5} \mathrm{~s}^{-1}$ for $\mathrm{CFC}-12$ at 203 and $288 \mathrm{~K}$ respectively. However, there are slight deviations in the linear relationship. These are not the result of the error of the measuring instrument as repeat measurements are very close. Rather, these are ascribed to possible moisture condensation on the reactor (despite ventilation) reducing light intensity, variations in reactor-lamp alignment, or lamp intensity variation. Alignment variations can occur in the photolysis setup as the reactor must be occasionally dismounted to remove accumulated bubbles in the reactor cooling fluid. Additionally, although no discernable lamp intensity instability was reported in previous research with this same lamp (Röckmann et al., 2000 and 2001; Kaiser et al., 2002 and 2003), it is possible that such instability has developed over time.

However, the aforementioned nonlinearity in the data in Fig. 5a and $\mathrm{b}$ does not impact the validity of these results for the calculation of $\varepsilon$ as the data plotted in Rayleigh fractionation plots (Fig. 5c and d) are very well correlated, with least-square $r^{2}$ values above 0.98 . This result suggests that any lamp intensity variations that alter the amount of photolysis that takes place in the reactor during at a given elapsed photolysis time does not affect the fractionation inherent in the photolysis reaction. At all temperatures, isotope fractionations are far larger for CFC-12 than for CFC11. The strongest fractionations are observed at $203 \mathrm{~K}$, $(-66.2 \pm 3.1) \%$ o for CFC-12 and $(-23.8 \pm 0.9) \%$ for CFC11. The magnitudes of the isotope fractionations become larger (i.e. $\varepsilon$ becomes more negative) towards lower temperatures, similar to the situation with $\mathrm{N}_{2} \mathrm{O}$ (Kaiser et al. 2002). It is interesting to note that the $\mathrm{CFC}-12$ fractionations are similar in magnitude to the fractionation in the reaction $\mathrm{CH}_{4}+\mathrm{Cl}$ (Saueressig et al., 1995) or the reaction $\mathrm{CH}_{3} \mathrm{Cl}+\mathrm{OH}$ (Gola et al., 2005). 

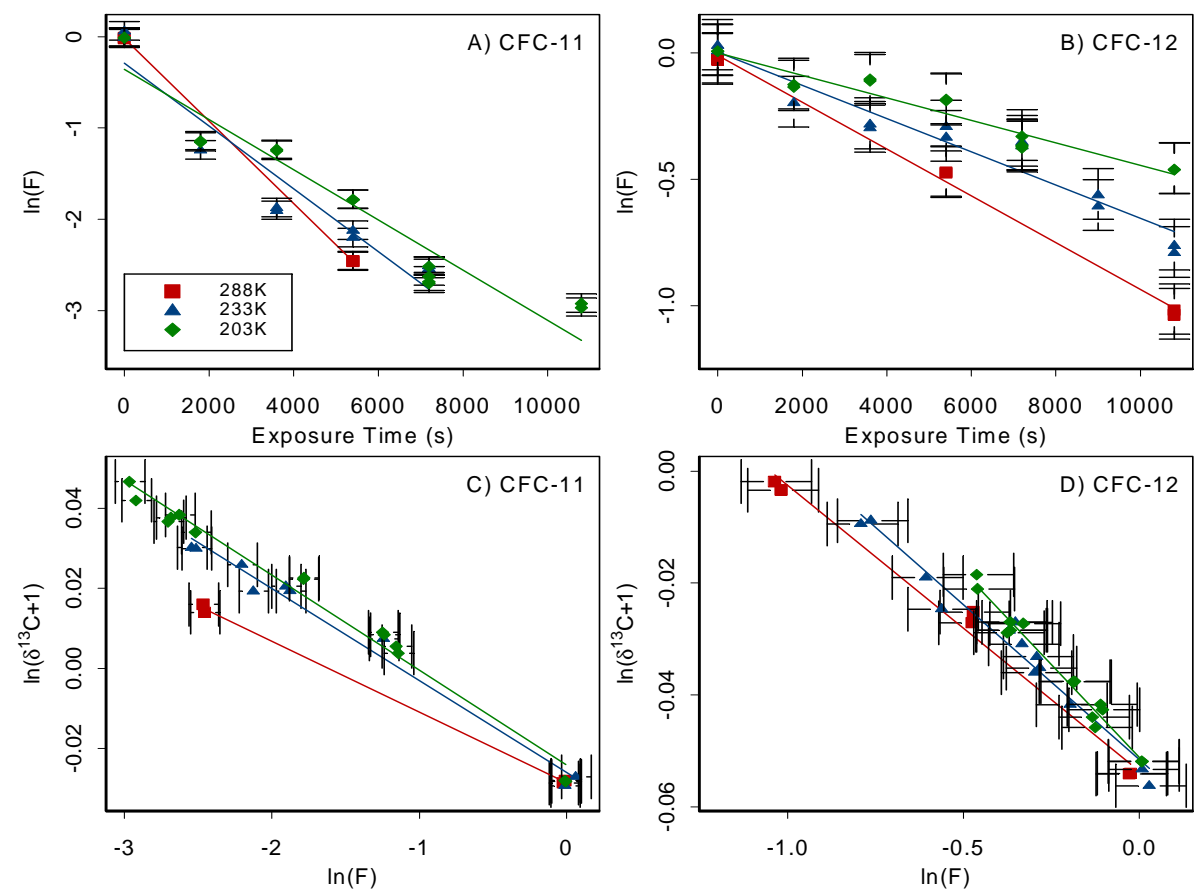

Fig. 5. Plots of $\ln (\mathrm{F})$ vs. exposure time in seconds (panels $\mathbf{A}$ and $\mathbf{B})$ and $\ln \left(\delta^{13} \mathrm{C}+1\right)$ vs. $\ln (\mathrm{F})$ (panels $\mathbf{C}$ and $\left.\mathbf{D}\right)$ for samples at different exposures and temperatures for CFC-11 and -12 with least-squares fits to obtain $J$ and $\varepsilon$. The instrument used has $\pm 10 \%$ uncertainty for mixing ratio measurement, and its $\delta^{13} \mathrm{C}(1 \sigma)$ error is 0.9 and $0.7 \%$ for CFC-11 and -12 respectively. Summary of $J$ and $\varepsilon$ values from fits in Table 1 .

In the stratosphere, CFC-11 photodissociates faster than CFC-12 and its atmospheric lifetime is shorter by approximately a factor of 2 (Forster et al., 2007). In our experiments, the photolysis rate of CFC-11 is also faster, but by a factor of 5 . The difference can be explained by the fact that the lamp spectrum and the solar actinic flux at altitudes where CFC photolysis occur (19-34 km, Laube et al., 2010a) do not match (see Figs. 2 and 3). Integrating the product of the intensity (both Sb-lamp and $30 \mathrm{~km}$ solar) and absorption spectra, we calculate that the difference between the CFC-11 and -12 photolysis rates is approximately 1.7 times greater in the reactor than in the atmosphere, explaining a large part of the observed discrepancy.

This mismatch in UV-C wavelengths may also impact calculated fractionations as these have been shown to be wavelength dependent in laboratory $\mathrm{N}_{2} \mathrm{O}$ photolysis experiments. On the other hand, laboratory fractionations obtained with this same lamp are considered to be in good agreement with stratospherically observed fractionations, excepting the impact of dynamic processes, which reduce the magnitude of the fractionation by about half (Röckmann et al., 2001; Kaiser et al., 2006; Laube et al., 2010a). Ascertaining the scale of wavelength dependence is beyond the scope of this study and is a viable point of examination for future experiments.

In addition, interaction of CFC-11 and -12 with photolysis products and photolysis product recombination cannot be ex- cluded in our experiments and could potentially be an issue. However, Rebbert and Ausloos (1975) note that any remnant complex molecules (e.g. $\mathrm{CF}_{2}$ or $\mathrm{CF}_{2} \mathrm{Cl}$ ) are unreactive to their parent molecules. Additionally, chlorine abstraction from an intact halocarbon molecule due to interaction with radical chlorine is a very slow process due to the bond energies involved (Alapi et al., 2007). Recombination of chlorine with CFC radicals from photolysis to reform CFCs, on the other hand, is a real possibility. The rate of recombination is dependent on the mixing ratios of the CFC radicals and chlorine. Initial products of photolysis are radicals, which rapidly react with impurities either on the wall of the reactor or in the gas phase. The box model used to evaluate this took into account the photolysis rates of $\mathrm{Cl}_{2}$ and $\mathrm{CFC}$ compounds and the recombination of the radicals with $\mathrm{Cl}_{2}$ :

$$
\begin{aligned}
& \mathrm{CF}_{2} \mathrm{Cl}_{2}+h v \longrightarrow \mathrm{CF}_{2} \mathrm{Cl}+\mathrm{Cl} \\
& \mathrm{Cl}_{2}+h v \longrightarrow \mathrm{Cl}+\mathrm{Cl} \\
& \mathrm{Cl}+\mathrm{Cl}+M \longrightarrow \mathrm{Cl}_{2}+M \\
& \mathrm{CF}_{2} \mathrm{Cl}+\mathrm{Cl}_{2} \longrightarrow \mathrm{CF}_{2} \mathrm{Cl}_{2}+\mathrm{Cl} \\
& \mathrm{CF}_{2} \mathrm{Cl}+X \longrightarrow \text { products } \\
& \mathrm{Cl}+X \longrightarrow \text { products }
\end{aligned}
$$

Reactions (R5-R8) have been assumed to occur at fast rates of $3 \times 10^{-11} \mathrm{~cm}^{3} \mathrm{~s}^{-1}$, and photolysis rates (Reactions R3, R4) 
have been calculated by folding the absorption cross section of $\mathrm{Cl}_{2}$ and $\mathrm{CF}_{2} \mathrm{Cl}_{2}$ with the lamp spectrum, respectively. Results indicate that recombination is below $5 \%$ if impurities $(X)$ have an equivalent above $0.4 \mathrm{ppb}$ in the gas phase. Given the rather high concentrations of CFCs and the large surface/volume ratio of the reactor, we think that it is a conservative assumption that impurities exceeded this threshold. Therefore we think that recombination likely does not represent an issue to our results. However, we have to acknowledge that we cannot rule out possible recombination for $100 \%$. Further, any isotope effect in recombination is impossible to assess at this point as there is no data on the fractionations inherent in these reactions to our knowledge. Future experiments should be performed with well-defined levels of gases that can scavenge the produced radicals to definitively preclude any recombination.

Assuming the observed fractionations hold true in nature, these imply that there should be a strong vertical gradient in $\delta^{13} \mathrm{C}$ in the stratosphere for both CFC-11 and CFC-12, similar to the ones found for ${ }^{15} \mathrm{~N}-, \delta^{18} \mathrm{O}-\mathrm{N}_{2} \mathrm{O}$ (Röckmann et al., 2001), $\delta^{37} \mathrm{Cl}$ (Laube et al., 2010a) or $\delta^{13} \mathrm{CH}_{4}$ (Röckmann et al., 2011). The fractionations found here are very large and in particular stratospheric (photolytically aged) CFC-12 would then be expected to be exceptionally enriched in ${ }^{13} \mathrm{C}$.

For example, sample calculations using the measured fractionations at 203 and $233 \mathrm{~K}$ and a stratospheric profile of CFC-12 mixing ratio from Laube et al. (2010a) would indicate $\delta^{13} \mathrm{C}$ potential enrichments in excess of $60 \%$ compared to tropospheric values at $34 \mathrm{~km}$ altitude if the fractionations are applicable to the stratosphere. However, these are likely to be less due to the effect of atmospheric mixing, which causes apparent (observed) fractionation in the atmosphere $\varepsilon_{\text {app }}$ to be approximately half of the intrinsic (laboratory measured) fractionation. Unphotolyzed CFC is continuously brought into the stratosphere and mixed with CFC that has been photolyzed previously, changing the isotope ratio of the whole and suppressing the inherent fractionation (Röckmann et al., 2001; Kaiser et al., 2006; Laube et al., 2010a).

Similar to the situation for other long-lived trace gases, the fractionations in the removal reactions affect the tropospheric isotope budgets. This is because stratospherically processed air is transported down to the troposphere again after partial removal and corresponding isotope enrichment of the CFCs. In addition, a particular atmospheric signal is expected after the introduction of the Montreal protocol. As the emissions from sources have decreased significantly since 1990 (Forster et al., 2007), the isotope effect in the stratospheric removal reactions should be continuously enriching the entire tropospheric reservoir. This should continue for the coming decades as atmospheric CFC levels are decreasing and should also be observable in atmospheric air archives or polar firn air and eventually in ice cores, similar as to what has been ascertained in firn air for $\mathrm{N}_{2} \mathrm{O}$ nitrogen and oxygen stable isotopes (Röckmann et al., 2003).

\section{Conclusion}

A set of stable carbon isotopic fractionations in the UV-C $(190-230 \mathrm{~nm})$ photolysis reactions for CFC-11 and CFC-12 has been demonstrated. Strong isotope enrichments are associated with UV photolysis at environmentally relevant temperatures. The fractionations increase from $(-17.7 \pm 0.4) \%$ o and $(-51.0 \pm 2.9) \% 0$ at $288 \mathrm{~K}$ to $(-23.8 \pm 0.9) \% o$ and $(-66.2 \pm 3.1) \%$ at $203 \mathrm{~K}$ for the respective compounds. These fractionations imply that strong heavy isotope enrichments should be found in the stratosphere. Expected effects are isotope gradients with CFC removal (e.g. vertical and polewards) in the stratosphere (as have already been ascertained for chlorine isotopes through balloon samples), and a change of the stable carbon isotopic ratio of these compounds in the atmosphere over time.

Edited by: J. B. Burkholder

\section{References}

Advanced Global Atmospheric Gases Experiment (AGAGE) data, available at: http://agage.eas.gatech.edu/data.htm, last access: 10 November 2011, 2010.

Alapi, T., van Craeyenest, K., van Langenhoeve, H., Dewulf, J., and Dombi, A.: Direct VUV photolysis of chlorinated methanes and their mixtures in a nitrogen stream, Chemosphere, 66, 139-144, 2007.

Atkinson, R., Baulch, D. L., Cox, R. A., Crowley, J. N., Hampson Jr., R. F., Kerr, J. A., Rossi, M. J., and Troe, J.: Summary of evaluated kinetic and photochemical data for atmospheric chemistry, available at: http://www.iupac-kinetic.ch.cam.ac.uk/ summary/IUPACsumm_web_latest.pdf, last access: 12 April 2012, 2005.

Atkinson, R., Baulch, D. L., Cox, R. A., Crowley, J. N., Hampson, R. F., Hynes, R. G., Jenkin, M. E., Rossi, M. J., Troe, J., and Wallington, T. J.: Evaluated kinetic and photochemical data for atmospheric chemistry: Volume IV - gas phase reactions of organic halogen species, Atmos. Chem. Phys., 8, 4141-4496, doi:10.5194/acp-8-4141-2008, 2008.

Brenninkmeijer, C. A. M., Janssen, C., Kaiser, J., Röckmann, T., Rhee, T. S., and Assonov, S. S.: Isotope effects in the chemistry of atmospheric trace gases, Chem. Rev., 103, 5125-5162, 2003.

Blake, G. A., Liang, M. C., Morgan, C. G., and Yung, Y. L.: A BornOppenheimer photolysis model of $\mathrm{N}_{2} \mathrm{O}$ fractionation, Geophys. Res. Lett., 30, 1656, doi:10.1029/2003GL016932, 2003.

Butler, J. H., Battle, M., Bender, M. L., Monzka, S. A., Clarke, A. D., Saltzman, E. S., Sucher, C. M., Severinghaus, J. P., and Elkins J. W.: A record of atmospheric halocarbons during the twentieth century from polar firn air, Nature, 399, 749-755, 1999.

Engel, A., Schmidt, U., and McKenna, D.: Stratospheric trends of CFC-12 over the past two decades: recent observational evidence of declining growth rates, Geophys. Res. Lett., 25, 3319-3322, 1998.

Forster, P., Ramaswamy, V., Artaxo, P., Berntsen, T., Betts, R., Fahey, D. W., Haywood, J., Lean, J., Lowe, D. C., Myhre, G., Nganga, J., Prinn, R., Raga, G., Schulz, M., and Van Dorland, R.: 
Changes in Atmospheric Constituents and in Radiative Forcing. Climate Change 2007: The Physical Science Basis. Contribution of Working Group I to the Fourth Assessment Report of the Intergovernmental Panel on Climate Change, edited by: Solomon, S., Qin, D., Manning, M., Chen, Z., Marquis, M., Averyt, K. B., Tignor, M., and Miller, H. L., Cambridge University Press, Cambridge, UK and New York, NY, USA, 2007.

Gola, A. A., D’Anna, B., Feilberg, K. L., Sellevåg, S. R., BacheAndreassen, L., and Nielsen, C. J.: Kinetic isotope effects in the gas phase reactions of $\mathrm{OH}$ and $\mathrm{Cl}$ with $\mathrm{CH}_{3} \mathrm{Cl}, \mathrm{CD}_{3} \mathrm{Cl}$, and ${ }^{13} \mathrm{CH}_{3} \mathrm{Cl}$, Atmos. Chem. Phys., 5, 2395-2402, doi:10.5194/acp5-2395-2005, 2005.

Kaiser, J., Röckmann, T., and Brenninkmeijer, C. A. M.: Temperature dependence of isotope fractionation in $\mathrm{N}_{2} \mathrm{O}$ photolysis, Phys. Chem. Chem. Phys., 4, 4420-4430, doi:10.1039/b204837j, 2002.

Kaiser, J., Röckmann, T., Brenninkmeijer, C. A. M., and Crutzen, P. J.: Wavelength dependence of isotope fractionation in $\mathrm{N}_{2} \mathrm{O}$ photolysis, Atmos. Chem. Phys., 3, 303-313, doi:10.5194/acp3-303-2003, 2003.

Kaiser, J., Engel, A., Borchers, R., and Röckmann, T.: Probing stratospheric transport and chemistry with new balloon and aircraft observations of the meridional and vertical $\mathrm{N}_{2} \mathrm{O}$ isotope distribution, Atmos. Chem. Phys., 6, 3535-3556, doi:10.5194/acp6-3535-2006, 2006.

Laube, J. C., Kaiser, J., Sturges, W. T., Bönisch, H., and Engel, A.: Chlorine Isotope Fractionation in the Stratosphere, Science, 329, 1167, doi:10.1126/science.1191809, 2010a.

Laube, J. C., Martinerie, P., Witrant, E., Blunier, T., Schwander, J., Brenninkmeijer, C. A. M., Schuck, T. J., Bolder, M., Röckmann, T., van der Veen, C., Bonisch, H., Engel, A., Mills, G. P., Newland, M. J., Oram, D. E., Reeves, C. E., and Sturges, W. T.: Accelerating growth of HFC-227ea (1,1,1,2,3,3,3-heptafluoropropane) in the atmosphere, Atmos. Chem. Phys., 10, 5903-5910, doi:10.5194/acp-10-5903-2010, 2010b.

Massie, S. T. and Goldman, A.: Absorption parameters of very dense molecular spectra for the HITRAN compilation, J. Quant. Spectrosc. Radiat. Transfer, 48, 713-719, 1992.

Minschwaner, K., Salawitch, R. J., and McElroy, M. B.: Absorption of solar radiation by $\mathrm{O}_{2}$ : Implications for $\mathrm{O}_{3}$ and lifetimes of $\mathrm{N}_{2} \mathrm{O}, \mathrm{CFCl}_{3}$, and $\mathrm{CF}_{2} \mathrm{Cl}_{2}$, J. Geophys. Res., 98, 10543-10561, 1993.

Morgan, C. G., Allen, M., Liang, M. C., Shia, R. L., Blake, G. A., and Yung, Y. L.: Isotopic fractionation of nitrous oxide in the stratosphere: Comparison between model and observations, J. Geophys. Res., 109, D04305, doi:10.1029/2003JD003402, 2004.
Rahn, T. and Wahlen, M.: Stable isotope enrichment in stratospheric nitrous oxide, Science, 278, 1776-1778, 1997.

Rebbert, R. E. and Ausloos, P. J.: Photodecomposition of $\mathrm{CFCl}_{3}$ and $\mathrm{CF}_{2} \mathrm{Cl}_{2}$, J. Photochem., 4, 419-434, 1975.

Röckmann, T., Brenninkmeijer, C. A. M., Wollenhaupt, M., Crowley, J. N., and Crutzen, P. J.: Measurement of the isotopic fractionation of ${ }^{15} \mathrm{~N}^{14} \mathrm{~N}^{16} \mathrm{O},{ }^{14} \mathrm{~N}^{15} \mathrm{~N}^{16} \mathrm{O}$ and ${ }^{14} \mathrm{~N}^{14} \mathrm{~N}^{18} \mathrm{O}$ in the UV photolysis of nitrous oxide, Geophys. Res. Lett., 27, 1399-1402, 2000.

Röckmann, T., Kaiser, J., Brenninkmeijer, C. A. M., Crowley, J. N., Borchers, R., Brand, W. A., and Crutzen, P. J.: Isotopic enrichment of nitrous oxide $\left({ }^{15} \mathrm{~N}^{14} \mathrm{NO},{ }^{14} \mathrm{~N}^{15} \mathrm{NO},{ }^{14} \mathrm{~N}^{14} \mathrm{~N}^{18} \mathrm{O}\right)$ in the stratosphere and in the laboratory, J. Geophys. Res., 106, 10403-10410, 2001.

Röckmann, T., Kaiser, J., Brenninkmeijer, C. A. M.: the isotopic fingerprint of the pre-industrial and the anthropogenic $\mathrm{N}_{2} \mathrm{O}$ source, Atmos. Chem. Phys., 3, 315-323, doi:10.5194/acp-3-315-2003, 2003.

Röckmann, T., Brass, M., Borchers, R., and Engel, A.: The Isotopic Composition of Methane in the Stratosphere: High-Altitude Balloon Sample Measurements, Atmos. Chem. Phys., 11, 1328713304, doi:10.5194/acp-11-13287-2011, 2011.

Seinfeld, J. H. and Pandis, S. N.: Atmospheric Chemistry and Physics: from Air Pollution to Climate Change, John Wiley and Sons, New York, USA, 1326 pp., 1998.

Saueressig, G., Bergamaschi, P., Crowley, J. N., Fischer, H., and Harris, G. W.: Carbon kinetic isotope effect in the reaction of $\mathrm{CH}_{4}$ with $\mathrm{Cl}$ atoms, Geophys. Res. Lett., 22, 1225-1228, 1995.

von Hessberg, P., Kaiser, J., Enghoff, M. B., McLinden, C. A., Sorensen, S. L., Yung, Y. L., and Miller, C. E: Isotopic fractionation of stratospheric nitrous oxide, Science, 278, 1778-1780, 1997.

World Meteorological Organization (WMO): Global Ozone Research and Monitoring Project Report No. 52: Scientific Assesment of Ozone Depletion 2010, available at: http://ozone.unep. org, last access: 27 March 2012, 2010.

Zuiderweg, A., Holzinger, R., and Röckmann, T.: Analytical system for stable carbon isotope measurements of low molecular weight $\left(\mathrm{C}_{2}-\mathrm{C}_{6}\right)$ hydrocarbons, Atmos. Meas. Tech., 4, 11611175, doi:10.5194/amt-4-1161-2011, 2011. 